\title{
The Use of Secondary Data in Unveiling the Potential of Ethnic Markets
}

\author{
Alvin M. Chan \\ University of Western Sydney \\ E-Mail: a.chan@uws.edu.au \\ Farid Ahmed \\ University of Western Sydney \\ E-Mail: f.ahmed@uws.edu.au
}

\begin{abstract}
While there is an increasing number of companies realizing the potential that the diverse ethnic markets in Australia possess, majority still do not see the potential. When compared to the United States, ethnic marketing in Australia is still in a developmental stage. For many marketers, the problem is in knowing where to start. Looking from the practitioner's perspective, this paper demonstrates how to apply readily available secondary data in identifying the potential of the ethnic markets in Australia for selected goods and services. By showing where and how to start, we hope that more marketers in Australia will see the potential of ethnic marketing and in the long run ethnic marketing will be an integral part of any marketing campaign run by a company. Marketers should reassess the usefulness and importance of secondary data in facilitating their formulation of strategic marketing decisions in different marketing mix areas.
\end{abstract}

Keyword: Secondary Data, Ethnic Marketing, Marketing Planning, Segmentation, Australia

\section{INTRODUCTION}

Secondary data are information that has been previously collected for some other purposes other than the research project at hand, whereas primary data are information gathered and assembled specifically for the research objectives at hand. However, this does not mean that secondary data are "secondary" to primary data in the strategic marketing planning process. In fact, notwithstanding some limitations, secondary data provide cost and time savings. Some information, like population profiles, can be obtained only from Census statistics (see Aaker, Day, \& Kumar, 2004; Churchill \& Iacobucci, 2005; Cooper \& Schindler, 2003).

The objective of this paper is to demonstrate the practical usefulness of secondary data, when applied appropriately and intelligently, in identifying market potential such as the lucrative ethnic markets in Australia.

"Ethnic Marketing: Have You Seen the Potential?" is the headline of the advertisement placed by Cultural Perspectives Proprietary Limited, an ethnic marketing consultancy firm based in Sydney, in the Australian Professional Marketing (1995, p. 5). The copy of the advertisement 